\title{
Inovação gerencial na administração pública, cidadania e direitos dos brasileiros
}

\author{
Vera Lúcia Peixoto Mendes ${ }^{1}$
}

Resumo

Este trabalho discute a adoção de inovação gerencial na administração pública na perspectiva institucional. Parte-se dos pressupostos que a relação entre estado e sociedade civil é dialética e que as possibilidades de êxito das inovações gerenciais na esfera pública são limitadas se não estiverem apoiadas pelos cidadãos. Este apoio, contudo, é influenciado pelo entendimento de cidadania e dos direitos dos cidadãos, considerando-se que, para demandar serviços de qualidade, é necessário reconhecer-se enquanto cidadão portador de tais direitos. A inovação gerencial estudada é o Programa de Qualidade Total (PQT) implantado na esfera pública municipal. À luz da literatura sobre PQT discutem-se seus objetivos e valores, assim como a sua aplicabilidade ao setor público. Com bases no trabalho de Marshall (1950) e na Constituição Brasileira (1988) analisam-se a evolução histórica do conceito de cidadania e os direitos dos cidadãos. São discutidos os resultados de estudo empírico realizado em dois períodos de gestão municipal (1993-96 e 1997-2000), com 4.805 usuários dos serviços nos quais fora implantado o PQT. Conclui-se que a implantação da inovação gerencial contribuiu para ampliar o entendimento dos usuários sobre cidadania, porém não modificou o entendimento sobre os direitos sociais enquanto direitos dos brasileiros.

\begin{abstract}
This paper discusses the adoption of managerial innovation in the public administration from institutional perspective. There is a presupposition that the possibilities of success of the managerial innovations in the public sphere are limited if they are not supported by the main ones interested: the citizens-users of the public services. However, this support depends on the citizenship understanding and of the citizens' rights, being considered that, to demand quality services, it is necessary to recognize while citizen bearer of such rights. The studied managerial innovation is the Program of Total Quality implanted in the public sphere. Initially, the objectives are discussed, values, definitions that permeate this innovation, its applicability to the public services and the historical evolution of the citizenship concept. Later, results of empiric study are analyzed accomplished in two different periods of the municipal government's administration (1993-96 and 1997-2000), with 4.805 users of public services which was developed the Program. The results indicate that the implantation of the managerial innovation contributed to enlarge the users' understanding on citizenship, however it didn't modify the understanding on the citizens' rights in Brazil.
\end{abstract}

\footnotetext{
${ }^{1}$ Professora da Universidade Federal da Bahia. Doutora em Administração Pública.
} 


\section{Introdução}

$\mathrm{Na}$ administração pública, inovações gerenciais têm ocorrido em muitos países e nas diferentes esferas de governo. No entanto poucos estudos têm sido empreendidos para compreender como forças sociais diversas se articulam para dar nascimento às mudanças contemporâneas na gestão pública e qual o seu impacto sobre os sistemas de serviços públicos, particularmente na esfera municipal e no que se refere à cidadania e aos direitos dos cidadãos (Tenório, 1998, Draibe, 1986).

Neste trabalho, considera-se que inovação gerencial está vinculada a mudanças institucionais e organizacionais e que, portanto, pode ser tratada como importante questão de política pública. As razões para tratar reformas administrativas enquanto questão de política estão relacionadas à redução da confiança da sociedade civil nas instituições públicas e ao aumento da demanda social por reformas organizacionais (March \& Olsen, 1989).

As burocracias públicas tradicionais além de terem se tornado complexas, com características centralizadoras e estruturas rígidas, não têm sido orientadas para o atendimento das necessidades dos cidadãos, ou para a eficácia e efetividade, enfocando mais aspectos como a produtividade e eficiência. Para tanto, difundem-se no setor público inovações consideradas exitosas no setor empresarial, a exemplo dos Programas de Qualidade Total (PQT) sem que se considerem objetivos e valores predominantes na administração pública. Certamente os valores do mundo empresarial não são idênticos àqueles pertencentes à esfera pública. Assim, é oportuno discutir que tipo de valores as inovações, como os programas de qualidade procuram difundir no setor público.

$\mathrm{Na}$ esfera pública, as inovações trazem embutidas uma política de governo e uma expectativa de comportamento dos sujeitos envolvidos, ou seja, as inovações dependem dos mecanismos de interação existentes entre estado e sociedade civil. Deste modo, o sucesso de uma inovação, neste setor, dependeria da capacidade gerencial para adotá-las e implementálas, pois é na esfera do estado que os direitos são efetivados ou anulados e dependeria também da pertinência e adequação entre expectativas sociais e o efetivo conjunto de valores e atitudes predominantes entre usuários e prestadores de serviços, pois é na esfera da sociedade civil que os direitos são reconhecidos e defendidos.

A adoção de inovação gerencial na administração pública implica incluir o cidadão enquanto sujeito ativo e consciente dos seus direitos. No Brasil, significa a aprendizagem para o exercício da cidadania e para desempenho de novos papéis. Porém, não se sabe se as inovações gerenciais do tipo Programas de Qualidade Total têm propiciado esta aprendizagem ou se estão limitadas ao contexto das organizações, enquanto conjunto de práticas gerenciais estéreis e predestinadas a falhar.

À luz das mudanças organizacionais introduzidas nos contextos internacional $\mathrm{e}$ nacional, e, considerando-se a realidade das organizações públicas brasileiras prestadoras de serviços, busca-se discutir, neste trabalho, a relação entre inovação gerencial na administração pública e mudanças institucionais. Na esfera institucional, parte-se do pressuposto que as atitudes dos usuários são pautadas por normas institucionais e podem ajudar a compreender os resultados do PQT. Para tanto, toma-se como referência o Artigo 196 da Constituição da República Federativa do Brasil em que "a saúde é direito de todos e dever do Estado" (Brasil, 1988), ou seja, a saúde é um direito de cidadania. Assim, analisam-se as atitudes dos usuários de serviços públicos ante a inovação gerencial, discutindo-se em que medida estas inovações contribuem para elevar o grau de entendimento sobre cidadania e direitos dos cidadãos no Brasil. 


\section{Programas de Qualidade Total na administração pública: a que será que se destinam?}

O modelo de gestão da qualidade tem sido considerado uma revolução na administração e vem sendo tomado como uma alternativa inovadora em termos de gerenciamento empresarial (Deming, 1990). Enquanto modelo de gestão inovador, no setor empresarial a qualidade objetiva aumentar a produtividade, reduzir os custos, obter a satisfação do consumidor e elevar a competitividade.

O que significa inovação na administração pública? Para melhor compreender a inovação gerencial na esfera pública, procura-se entender a administração pública enquanto entidade que possui um aparato executivo e um aparato político (governo). Ao se diferenciar a administração do governo, delimitam-se duas instâncias de ação que se inter-relacionam, incorporando, desse modo, a dimensão política da administração pública.

No setor público, os programas de qualidade são considerados inovações gerenciais e se constituem em tentativas de interferir no modus operandi das organizações nas quais são implantados, ou seja, na forma de organizar a produção. Para efeito deste trabalho, a inovação gerencial na administração pública é caracterizada por modificações desencadeadas pelo governo e empreendidas nas organizações deste setor, que possibilitem o desenvolvimento de práticas transformadoras entre os sujeitos envolvidos na produção e no consumo dos serviços. Assim, a inovação gerencial é um processo que pode demandar e, ao mesmo tempo, provocar mudanças organizacionais e institucionais, estando a eficácia de sua adoção na administração pública condicionada a fatores de natureza histórica e social do contexto no qual estão inseridas, em estreita relação com a cultura cívica da população servida.

A abordagem da inovação gerencial na administração pública envolve diferentes níveis de compreensão: o macro, aqui entendido como o institucional, e o micro ou organizacional. Neste trabalho, prioriza-se a perspectiva institucional, buscando-se compreender como a inovação gerencial, denominada de Programa de Qualidade Total, atua no entendimento dos usuários de serviços públicos a respeito da cidadania e dos seus direitos.

As inovações gerenciais no contexto dos serviços públicos são semelhantes àquelas empreendidas no setor empresarial? Nos serviços públicos, a qualidade é reconhecida como um direito do cidadão (Gaster, 1999). No entanto, muitas condições necessitam ser preenchidas antes que as políticas de qualidade sejam efetivas. Para a autora, o gerenciamento top-down, as idéias preconcebidas ou as receitas de como executar o trabalho não funcionam, mas o entendimento sobre as políticas de qualidade e o comprometimento dos funcionários podem contribuir para o sucesso ou falhas de um programa de qualidade.

Pollitt (1994) discute a qualidade no serviço público, no contexto inglês, como uma questão que, na prática, visa a melhoria da eficiência para reduzir gastos, mantendo-se os níveis de qualidade do serviço. Ele define qualidade no setor público a partir de diferentes concepções, contemplando aquelas advindas dos aparatos político e executivo. Assim, este autor apresenta as definições de qualidade nas perspectivas de políticos, gerentes, funcionários públicos e usuários, afirmando que cada um tem sua própria definição. Com relação à definição de qualidade dos políticos, "as referências (...) são fáceis de encontrar, porém as definições que possam suportar um teste são escassas” (Pollitt, 1994:354).

$\mathrm{Na}$ visão dos gerentes, qualidade é definida em termos da existência de procedimentos para mudar, documentar e supervisionar variáveis escolhidas (Rooney, 1988, apud Pollitt, 1994). Isso aumenta a transparência do que está sendo feito pelos funcionários e torna o controle dos processos de trabalho mais facilitado, pois conta com normas e outros documentos gerenciais. Na ótica dos funcionários a qualidade é considerada como o produto de um longo período de treinamento e acúmulo de experiência prática. Estes podem ainda perceber os programas de qualidade como tentativas burocráticas e que não inovam (Pollitt, 1994). 
A multiplicidade de definições discutidas acima indica que a qualidade no serviço público está associada a objetivos estratégicos, derivados de valores, sejam estes explícitos, como na definição de missão e visão das organizações, ou implícitos. Valores como democracia, accountability, empowerment e comunidade são considerados a base da qualidade nos serviços públicos (Gaster, 1999). Assim, como preservar estes valores com a introdução de mecanismos de mercado, baseados em processos puramente gerenciais em detrimento da participação dos cidadãos?

Os objetivos do setor privado como o da competição e da lucratividade trazem questionamentos se os serviços públicos podem ser dirigidos para maximizar a renda e minimizar os gastos. Em que medida esses objetivos são compatíveis com eqüidade, igualdade e altruísmo, que são parte do sistema de valores do setor público? Afinal, qual o papel do cidadão no mundo dos paramercados, no qual a prestação de serviços essenciais é feita por organizações privadas?

Gaster (1999) destaca que mesmo organizações com objetivos já definidos podem ter dificuldades para mantê-los quando são implantados programas de qualidade. Estas dificuldades decorrem da substituição dos objetivos que orientam a esfera pública por aqueles associados aos sistemas empresariais e que são, geralmente, vinculados ao PQT.

No setor de serviços de um modo geral e, particularmente, na administração pública, pelo seu caráter de ser mão-de-obra intensiva, o enfoque gerencial é de grande importância para a qualidade. Neste setor, a qualidade depende dos sujeitos que praticam as ações e, principalmente, dos que sofrem a ação, ou seja, o cidadão. Assim, a definição de qualidade comporta ainda uma quarta visão: a do cidadão ou "usuário". Embora Pollitt (1994) reconheça a importância de incorporá-la na definição de qualidade na administração pública., ele não a desenvolve, constituindo-se uma das lacunas do seu trabalho.

Uma variedade de termos é usada para descrever aqueles que recebem serviços públicos: clientes (customers ou clients), usuários, consumidores e público (Hague, 1989, apud Gyford, 1991). Isso sugere que estes conceitos são usados de modo intercambiável, sem se preocupar com os significados. Geralmente, quando há dependência dos profissionais para prestar um serviço, usa-se o termo cliente, porém nos serviços sociais é mais comum o termo "usuário". A denominação "consumidor" é usada para expressar relações de troca com pagamento pelo serviço. O termo consumerism significa o estímulo aos atos de consumo de um produto ou serviço e abrange não só a defesa dos interesses do consumidor mas as virtudes do alto consumo, defendidas pelo capitalismo.

O amplo apelo ao consumo e sua orientação para o cliente (customer) reflete não só uma orientação apolítica de origem gerencial, mas uma estratégia de difusão destes conceitos (Gyford,1991). Deste modo, conclui-se que falar a linguagem do consumo e da escolha não é o mesmo que a linguagem do poder e do controle, pois o consumerism não provoca uma mudança radical na distribuição de poder e não encoraja os consumidores a levarem em conta as preferências e os direitos dos outros (Gyford, 1991). Segundo o autor, a lógica das organizações públicas não é meramente consumista. Assim, ele sugere que seria necessário mudar de um foco instrumental sobre o consumo para o foco sobre o cidadão e noções de cidadania, o que abrange o reconhecimento dos direitos dos outros e a importância dos deveres e direitos (Gyford, 1991:169).

Como pode o cidadão se beneficiar dos programas de qualidade no serviço público? A literatura sobre implantação de programas de qualidade foca sobre fatores organizacionais e indica que a mudança cultural é uma importante estratégia para o sucesso da iniciativa. Contudo, usualmente, essa literatura não trata da mudança cultural na perspectiva do cidadão e não aborda aspectos referentes à importância do seu conhecimento sobre os processos que ocorrem na organização como forma de aumentar o seu poder de barganha, por meio da 
participação. Ou seja, o cidadão é tratado como cliente e este enquanto um ente à parte, alguém cuja participação se limita ao poder de compra, mediado pelas relações de mercado.

Para Gaster (1999), a baixa qualidade dos serviços públicos gera e perpetua uma baixa expectativa em relação ao que pode ser oferecido, tanto por usuários quanto pelos prestadores de serviços, contribuindo assim para gerar um ciclo vicioso de insatisfação e frustração de gerentes e usuários. Neste cenário, as alternativas para os usuários têm sido o abandono do serviço (exit) e, para os gerentes, a implantação de práticas gerenciais consideradas exitosas no setor privado.

Tanto a literatura quanto as práticas voltadas para a implantação de inovações gerenciais no setor público procuram desconhecer as diferenças entre os setores público e privado. Denominar os indivíduos que fazem uso dos serviços públicos de consumidores, usuários, clientes ou pacientes (no caso do setor saúde), não é só uma questão etimológica, mas parece fazer parte de uma estratégia que objetiva maximizar os atos de consumo.

Santos (1998:41) apresenta uma distinção entre consumidor e cidadão. Para ele:

... consumidor não é o cidadão (...). Consumidor alimenta-se de parcialidades, contenta-se com respostas setoriais, alcança satisfações limitadas, não tem direito ao debate sobre os objetivos de suas ações públicas ou privadas (...) cidadão é multidimensional, (...), em que cada dimensão se articula com as demais na procura de um sentido para a vida e faz dele um ser em busca de futuro, um homem à altura do seu tempo histórico.

Para Hirschman (1983) os atos de consumo, do mesmo modo que os de participação em questões públicas, são realizados porque se espera que gerem satisfação. No entanto, estes atos são potencialmente geradores de decepção e insatisfação. $O$ entendimento das reações às decepções pode ser proporcionado pela teoria econômica tradicional. Se importantes experiências de consumo privado deixam decepção e frustração, e se, ao mesmo tempo, o consumidor decepcionado encontra um tipo diferente de "busca de felicidade", uma possível dedução, com base nessa teoria, é que ele abrace essa busca. Porém, ressalta Hirschman, isso ocorre se os consumidores estiverem conscientes de que são cidadãos e viverem em uma cultura em que público e privado sejam importantes categorias dicotômicas que estão em permanente competição pelas atenções e tempo do cidadão-consumidor .

A reação à decepção é entendida pela Teoria da Escolha Pública como o "afastamento" ou (exit), no sentido de abandonar o consumo de um produto ou serviço. Para Hirschman, existe outra saída que é manifestar-se, engajando-se em ações que vão da reclamação individual até à ação popular de interesse geral (voice). Na maioria dos casos, a manifestação é uma ação pública por natureza e pode enfraquecer a reação do tipo afastamento, aumentando a tendência à mudança das ações na esfera pública. Portanto, a possibilidade de manifestar-se está associada ao auto-reconhecimento enquanto cidadão e a saída, "ir embora", associa-se ao comportamento do consumidor.

A possibilidade de escolha por parte do "usuário" é tratada pela Teoria da Escolha Pública (Olson, 1971; Sandler, 1992) como garantia de qualidade e a saída (exit), no sentido de abandonar aquele prestador de serviço que não corresponde às suas expectativas, é considerada como o mecanismo mais efetivo de mudança organizacional. No entanto, a pressão do "usuário" parece ser um fator importante na implantação de melhorias, mas não o único. A alternativa de saída (ir embora) pode até ser a mais adequada em determinados contextos e estruturas de mercado. Entretanto, convém lembrar que muitos "usuários" não disporão de outras alternativas, de modo que o "poder" de saída não é uma opção entre serviços que estão dominados pelos que os oferecem. Além de tudo, o poder de escolha geralmente está relacionado ao conhecimento decorrente do acesso a informações corretas. Para isso, torna-se necessário a existência de canais regulares de acesso às informações sobre 
os direitos nos quais irão apoiar-se quando não tiverem suas demandas atendidas (Pollitt, 1994).

$\mathrm{Na}$ perspectiva da gestão da qualidade total, nos moldes empresariais, o cliente é o elemento mobilizador das relações no mercado de bens de consumo. Na ótica do setor público e na perspectiva institucional, a importância recai sobre o cidadão. Entretanto esta parece ser uma dimensão esquecida, quando se estuda a introdução de inovações na administração pública.

\section{Cidadania, direitos e inovação gerencial}

O que significa ser cidadão e quais os seus direitos no contexto da introdução de inovações gerenciais no setor público? O conceito de cidadania não é estático, mas produzido geográfica e temporalmente. A partir do final do século XIX, mudanças ideológicas acompanharam as mudanças nas estruturas econômica e social das sociedades industrializadas e em processo de industrialização (Porter, 1999). Estas mudanças resultaram em renegociação da relação entre Estado e sociedade civil com implicações para o significado da cidadania na sociedade moderna (Draibe, 1986). Assim, entende-se que a noção de cidadania de uma determinada sociedade é o núcleo articulador entre os eixos organizacional e institucional das inovações que se estão introduzindo na administração pública.

No século XX, uma das principais contribuições sobre a constituição dos direitos de cidadania, no campo teórico, veio de Marshall. Para ele, a cidadania seria composta dos direitos civis, políticos e sociais. Marshall formulou, a partir da experiência inglesa, uma sequiência progressiva sobre os direitos, o que conferiu ao seu discurso, as características de uma "teoria geral da mudança social".

De acordo com a definição de Marshall (1950), os direitos civis, conquistados no século XVII, em resposta ao absolutismo, significariam liberdade individual de falar, pensar e acreditar, o direito à propriedade, o direito de ir e vir, o direito à realização de contratos, à justiça, à vida e à segurança. Os direitos políticos, desenvolvidos com a evolução da moderna democracia parlamentar, foram alcançados no século XIX e incluíam o direito de participar do poder político como membro de uma sociedade, investido de autoridade política ou como eleitor. Os direitos sociais, uma conquista dos países de capitalismo avançado, no século XX, seriam a extensão do bem-estar econômico e social, necessários para se viver uma vida civilizada, obedecendo padrões que são relativos a uma dada sociedade. Em geral, correspondem, principalmente, aos direitos à saúde, à educação e ao seguro-desemprego, enfim, ao bem-estar social. Estes direitos são alcançados mediante a prestação de serviços sociais pelo Estado, inclusive o acesso ao sistema educacional (Barbalet, 1993, Santos, 1979).

$\mathrm{Na}$ visão marshalliana, os direitos civis e políticos tornaram-se a precondição para a extensão dos direitos sociais. $O$ direito a igual participação política foi desenvolvido na democracia emergente dos Estados-nação no século XIX, constituindo o núcleo da cidadania (Turner, 1993). A partir do início do século XX, às demandas organizadas dos trabalhadores, através de negociações coletivas, acrescentou-se a questão das desigualdades para estabelecer os direitos sociais, de acordo com um padrão de vida histórico de cada sociedade.

De acordo com o pensamento evolucionista de Marshall, os direitos sociais se originaram dos direitos civis. Ele afirmava que, no campo econômico, o direito civil básico era o direito ao trabalho (Marshall, 1950:10). A redução das desigualdades era um prérequisito para alcançar os direitos sociais, e que a política social, sobre a qual se estabeleceu um consenso nacional mínimo, estava ligada à institucionalização da cidadania social.

A visão de Marshall tem sido amplamente debatida e alvo de muitas críticas, dentre as quais algumas merecem destaque: o etnocentrismo, ou seja, o fato de suas assertivas estarem relacionadas ao contexto inglês, não podendo assim se generalizar; a sua visão evolucionária, 
ao estabelecer os direitos civis como precursores dos direitos políticos e estes antecedendo aos direitos sociais. Para Turner (1993), diferentes grupos sociais podem experimentar uma ordem diferente da descrita por Marshall e cita como exemplo as mulheres, que podem ter alcançado um certo nível de direitos sociais antes de seus direitos civis e políticos terem sido plenamente desenvolvidos. Outro aspecto pelo qual o autor é criticado refere-se à ausência do papel das classes sociais na conquista dos direitos, indicando que a transição para a cidadania foi gradual e pacífica.

O conceito de cidadania de Marshall, carece de discussões sobre as preocupações das minorias, tão presentes nos tempos atuais; sobre os efeitos da migração internacional e sobre a relação entre cidadania e direitos humanos. Estas lacunas revelam a sua incapacidade de prever a globalização econômica e as suas conseqüências, como a perda de autonomia do Estado-nação e as implicações disso para a cidadania (Turner, 1993; Bulmer \& Rees, 1996; Reis, 1997; Vieira, 1997).

A partir das críticas à definição marshalliana de cidadania, Turner (1993) considera que a cidadania corresponde ao "conjunto de práticas (jurídicas, políticas, econômicas e culturais) que definem uma pessoa como um membro efetivo da sociedade, o que traz como conseqüência o dimensionamento do fluxo de recursos para indivíduos e grupos sociais". Assim concebida, a cidadania é uma conseqüência de lutas políticas, da distribuição desigual de recursos e faz parte de uma dinâmica histórica, na qual se incluem os novos movimentos sociais. Nesta definição, Turner engloba direitos e deveres sociais, o tipo desses direitos (cidadania ativa e passiva), a forma como são distribuídos entre os diferentes setores da sociedade (modos de participação) e a dimensão cultural da cidadania, ou seja, enfoca a sua dimensão política, trazendo o cidadão para o epicentro do assunto. Entretanto Turner procura divorciar a definição de cidadania do conceito de Welfare State. Ou seja, o Estado-nação, tão importante na visão marshalliana, é abolido da definição de Turner.

Reis (1997) traça uma tipologia de cidadania, que, segundo ela, poderia servir tanto para sociedades desenvolvidas como em desenvolvimento. Recorrendo a Dumont, a autora observa que: “(...) todo Estado-nação tem que escolher, de alguma maneira entre a imagem de uma nação como uma coleção de indivíduos ou como indivíduos coletivos" (Reis, 1997:13). Para Reis (1997:13), a escolha entre "a nação como uma coleção de indivíduos ou como indivíduos coletivos está na raiz do capitalismo desenvolvido, cuja ênfase sobre o indivíduo coletivo significa um obstáculo aos direitos civis e políticos, enquanto os direitos sociais tornam-se uma dádiva das autoridades". A deliberada construção do público como uma coleção de indivíduos torna mais fácil para os governantes gerenciarem as políticas públicas do que se fosse dado um tratamento coletivizante.

Santos (1979) utiliza a cidadania regulada como o conceito-chave para entender a política econômica e social brasileira no pós-30. Para Santos (1979), no Brasil, as raízes da cidadania se encontram em um sistema de estratificação ocupacional, definido por norma legal e não por um código de valores políticos. Ou seja, são considerados cidadãos todos aqueles que possuem uma profissão e "os direitos do cidadão restringem-se aos direitos do lugar que ocupa no processo produtivo, tal como reconhecido por lei” (Santos, 1979:68). Aqueles que não possuíssem uma profissão ou que tivessem uma ocupação desconhecida por lei, compunham o grupo dos "pré-cidadãos", inflando o mercado informal de trabalho e a marginalidade. Neste contexto, os parâmetros para definição de cidadania são a regulamentação das profissões, o sindicato público e a carteira profissional, sendo esta, "a certidão de nascimento cívico" e o instrumento jurídico comprovante do contrato entre o Estado e a cidadania regulada (Santos, 1979:69).

De um lado, observa-se que o processo de reestruturação produtiva tem demandado cidadãos cada vez mais conscientes e capazes de reivindicar os seus direitos, principalmente o de estar capacitado a disputar a sua inserção no mercado de trabalho. Por outro lado, o 
processo de reestruturação do Estado, na forma pouco democrática como vem ocorrendo nas economias em desenvolvimento, pode servir para confundir duas entidades políticas diferentes: cidadãos e consumidores.

Tenório (1998) discute o conceito de cidadania e sua relação com a gestão social orientada pela racionalidade comunicativa, a partir da teoria crítica de Habermas. Para tanto, este autor enfatiza o conceito de cidadania deliberativa apoiado na concepção republicana, na qual os cidadãos agem como "atores políticos responsáveis de uma comunidade de pessoas livres e iguais" (p.18). Neste sentido, para que uma inovação gerencial na administração pública pudesse ter uma base de sustentação, seria fundamental que estivesse apoiada na cidadania deliberativa, que sugere que a "pessoa, ao tomar ciência de sua função como sujeito social e não adjunto (...) deve atuar não somente como contribuinte, eleitor, mas com uma presença ativa e solidária nos destinos de sua comunidade" (Tenório, 1998:19).

Observam-se que diferentes leituras sobre o que significa ser cidadão podem ser feitas. No contexto das inovações pautadas na qualidade total e que estão sendo adotadas pela administração pública, o cidadão é tratado como "cliente ou consumidor", o que significa posicionar-se como um sujeito cujo poder se resume à capacidade de consumo de bens e serviços ofertados pelo mercado. Neste sentido, a expressão das insatisfações é o abandono do serviço pelo usuário.

Outro significado predominante é a cidadania referente à nacionalidade, ou seja, à nação como "conjunto de habitantes de um território". Este significado não expressa as diferenças existentes entre os habitantes de uma nação e as conseqüências dessas diferenças nas reivindicações por bens de uso coletivo. De acordo com Turner (1993), o conceito de direitos humanos tem sido defendido como importante complemento à idéia de cidadania, pois se fundamenta em um sistema político global, sendo mais realista e progressivo do que o tradicional e nacional conceito de cidadania. Esta visão é contestada por Dittgen que afirma que, em um mundo onde tudo é intercambiável e fluido, a necessidade de possuir uma identidade coletiva se torna mais forte. Assim, para o autor, o Estado-nação continua sendo a mais importante instituição para assegurar o papel da lei e a tese do declínio da importância da cidadania é conseqüientemente também uma variação da tese do fim do Estado-nação. Assim o autor afirma:

Até mesmo nos Estados Unidos, de acordo com a nova legislação de bem-estar, direitos sociais estão reservados para os cidadãos, restringindo-se para os migrantes legais. Deste ponto de vista, os direitos sociais, o Estado-nação e a cidadania são tão mais importantes agora quanto sempre foram (Dittgen, 1999:176, passim) (Tradução da Autora).

Dittgen (1999) afirma que não é convincente a noção de que cidadania e residência legal serão definidas pelo regime dos direitos internacionais. Para ele, o mais importante argumento para contestar a tese de pertencimento pós-nacional não é só o fato de os cidadãos possuírem direitos políticos básicos, tais como o direito ao voto, mas efetivamente o de que a cidadania continua sendo a instituição fundamental que conecta o indivíduo portador de direitos às agências do Estado. A arena política na qual os cidadãos agem juntos, permanece definida por fronteiras entre as nações.

Ao mesmo tempo que o Estado-nação é importante para a cidadania, verifica-se uma crise de sua autonomia, na qual as condições econômicas não são definidas pelos governos locais. Entretanto estes podem adotar políticas públicas para facilitar a ação coletiva, envolvendo o público em projetos educacionais voltados ao desenvolvimento de competências técnicas e políticas e apoiando iniciativas que facilitem a participação na administração pública (Gyford, 1991). Em princípio, os programas de qualidade deixam implícita a idéia da participação (voice) dos usuários para evitar o abandono do serviço (exit).

A partir do momento em que são introduzidas novas formas de gerenciamento na administração publica, nota-se que também são introduzidas novas concepções de cidadania, juntamente com mudanças ideológicas e culturais. Estas inovações gerenciais originadas da 
esfera privada, contemplam "novas" formas de participação, fazendo com que ganhem um caráter mais abrangente do que simplesmente encará-las como mudança na forma de administrar, como inicialmente se poderia supor.

É no espaço do público que a cidadania se efetiva, dependendo assim, dentre outros requisitos, do entendimento que os indivíduos têm sobre cidadania e seus direitos enquanto cidadãos. O Estado gerencial contém um conjunto de idéias e valores que se sustentam no individualismo, na introdução de mecanismos de mercado, no consumerism e na razão instrumental enquanto modelo de gestão das organizações públicas. Ante este modelo, o real debate é se inovações pautadas na lógica do mercado podem propiciar maior controle democrático por parte dos usuários dos serviços. Hoje, novos movimentos sociais, mais do que a luta de classes são responsáveis pela expansão da cidadania. A cidadania continua o epicentro nos conflitos sociais, considerando-se um equívoco pensar que, no contexto da globalização econômica, o Estado-nação deixaria de ser a célula germinativa para a expansão da cidadania e dos direitos dos cidadãos.

A cidadania enquanto conjunto de práticas cultural e socialmente construída remete a um dado contexto: o Estado nacional. Deste modo, o entendimento sobre cidadania e os direitos dos cidadãos faz parte do conjunto de reformas que se estão processando lentamente para, mais uma vez, acomodar tensões ocorridas no regime de acumulação. O conhecimento sobre o significado da cidadania não necessariamente levaria à ação participativa dos cidadãos mas poderia ajudar nos processos de mudanças organizacional e institucional. No pós-Segunda Guerra, a cidadania mudou a qualidade do conflito social. Hoje a(s) cidadania(s) continua $(\mathrm{m})$ fazendo parte do ideal democrático, sendo importante para as economias desenvolvidas e, muito mais, para aquelas em desenvolvimento.

Ante a importância da cidadania e do entendimento sobre os direitos dos cidadãos para a implantação de inovações gerenciais na administração pública, procura-se a seguir situar e analisar algumas evidências empíricas que fundamentam esta relação. Neste estudo, enfocase a cidadania na perspectiva republicana, que vê o cidadão como portador de virtudes que o orientam para o mundo público, ou seja, enquanto um conjunto de direitos e deveres ante os outros, o Estado e a sociedade, ou enquanto ideal liberal, cuja cidadania é outorgada pelo Estado e cujos valores são orientados para o consumo e para o mundo privado, priorizando qualidades pessoais positivas e autonomia e riqueza.

\section{Procedimentos metodológicos}

Desenvolveu-se um estudo comparativo, de dois cortes transversais (1996 e 1998) nos serviços municipais de saúde de Salvador. Em 1996 as dezenove unidades operacionais da Secretaria Municipal de Saúde foram classificadas ${ }^{\mathrm{i}}$ segundo o grau de implantação do PQT, selecionando-se uma amostra aleatória de nove unidades (três de cada grau de implantação). Como instrumentos de coleta de dados, foram realizadas entrevistas com representantes dos Conselhos Locais de Saúde e aplicados questionários com usuários em situação de uso do serviço de saúde, que freqüentavam a unidade por três ou mais vezes. O questionário apresentava questões abertas sobre a percepção dos usuários quanto à cidadania e aos direitos dos cidadãos no Brasil. A amostra de usuários foi calculada considerando uma previsão da proporção populacional de $50 \%$ e um nível de confiabilidade de $95 \%$, resultando em 2.402 pessoas em 1996 e 2.403 em 1998, não havendo recusas. A coleta de dados foi realizada por entrevistadores (universitários treinados) sem ligação formal com os serviços.

As respostas das questões relativas ao entendimento dos usuários sobre cidadania e direitos do cidadão no Brasil foram codificadas. A codificação das respostas sobre cidadania teve como referência os estudos de Marshall (1950), Reis (1997) e Santos (1979) e sobre os direitos dos cidadãos, considerou-se a Constituição Brasileira (1988). A análise das variáveis 
referentes ao indicador atitudes de usuários ante a inovação gerencial na administração pública deu-se mediante cálculo de proporções e intervalos de confiança a $95 \%$.

\section{Entendimento de Cidadania por grau de Implantação do PQT e período}

Em 1996, a análise estatística revela que, para a variável "não sabe/não responde" o que é ser cidadão, são apresentadas diferenças estatisticamente significantes entre as unidades de grau I (implantação mínima - 47,5\%) e grau III (implantação máxima - 43,2\%) e entre as unidades de grau II (implantação média -50,4\%) e grau III (Tabela 1). Já em 1998, para esta variável, a análise estatística apresenta diferenças significantes entre as unidades de todos os graus de implantação indicando que, quanto menor é o grau de implantação, maiores são os percentuais para este tipo de resposta $(60,3 \%$, nas unidades de grau I; 42,9\%, nas de grau II e 20,4\%, nas de grau III - Tabela 2). Em 1996, os usuários das unidades de grau II apresentam maior desconhecimento em relação à cidadania $(50,4 \%)$ e, em 1998, os usuários das unidades de grau I $(60,3 \%)$. De um período a outro, observa-se que para esta variável aumenta a proporção de respostas nas unidades de grau I $(12,8 \%)$ e reduz nas unidades de graus II $(7,5 \%)$ e III $(22,8 \%)$ (Tabelas 1 e 2). Estes dados indicam mudanças no que se refere ao conhecimento dos usuários quanto ao indicador entendimento de cidadania. Estas mudanças podem ser consideradas negativas, nas unidades de grau $\mathrm{I}$, nas quais aumenta $\mathrm{O}$ desconhecimento sobre cidadania, em 1998, e positivas nas unidades de graus II e III. Assim, o grau de implantação do PQT parece contribuir para reduzir o desconhecimento dos usuários dos serviços públicos sobre cidadania. Contudo estas mudanças podem ser tanto no sentido de fortalecer a concepção individualista, quanto a concepção coletivista da cidadania.

Em 1996, para a variável cidadania como "qualidades pessoais positivas se diferenças estatisticamente significantes entre as unidades de grau I $(27,7 \%)$ e III $(34,3 \%)$ e entre as unidades de grau II $(30,1 \%)$ e III. Em 1998, esta variável continua apresentando diferenças estatisticamente significantes entre as unidades de grau I $(17,9 \%)$ e III $(24,9 \%)$ e entre as unidades de grau II (21\%) e III. Ou seja, nos dois períodos, as unidades de grau III são as que apresentam maiores percentuais de respostas que identificam a cidadania com "qualidades pessoais positivas", privilegiando, assim, a visão individualista da cidadania. Quanto mais avançado o grau de implantação do PQT maiores são os percentuais de respostas que identificam a cidadania com "qualidades pessoais positivas", significando que, em relação a esta variável, o grau de implantação do programa influenciou as atitudes dos usuários. Em relação a esta variável, quando comparados os dois períodos, observa-se redução, em 1998, para as unidades com diferentes graus $(9,8 \%$ entre as unidades de grau I, $9,1 \%$, grau II e 9,4\%, grau III - Tabelas 1 e 2).

Com relação à variável cidadania como "autonomia e riqueza", em 1996, observam-se diferenças estatisticamente significantes entre as unidades de grau I $(4,8 \%)$ e II $(1,3 \%)$ e entre II e III (4,3\%) (Tabela 1). Em 1998, para esta variável, observam-se diferenças significantes entre as unidades de grau I $(2,9 \%)$ e III $(6,4 \%)$ e entre II $(3,2 \%)$ e III. Para o total das unidades, nos dois períodos, são baixos os percentuais de respostas que identificam cidadania com autonomia e riqueza (3,1\%, em 1996 e 3,9\%, em 1998, Tabelas 1 e 2). Em 1996, as respostas dos usuários das unidades de grau I apresentam os maiores percentuais para esta variável (4,8\% - Tabela 1). Já em 1998, estas unidades são as que apresentam os menores percentuais para esta variável $(2,9 \%)$ e as unidades de grau III apresentam os maiores percentuais $(6,4 \%$ - Tabela 2). Isso pode indicar que o grau de implantação do PQT também influenciou positivamente as atitudes dos usuários em relação ao entendimento de cidadania como "autonomia e riqueza".

No que se refere à variável cidadania como "direitos e deveres ante outros, Estado e sociedade", a análise comparativa dos dois períodos demonstra que, para o total de respostas, 
há aumento de 8,4\% em 1998, em relação a 1996. Este aumento, contudo, é observado principalmente nas unidades de grau III nas quais o PQT foi considerado mais avançado. Em 1996, para esta variável, não são observadas diferenças estatisticamente significantes entre as unidades com diferentes graus de implantação do PQT. Já em 1998, observam-se diferenças estatisticamente significantes entre as unidades de todos os graus (10,3\%, para as unidades de grau I; 19,8\%, para de grau II e, 40,4\%, para as de grau III - Tabela 2). Além disso, em 1998, obtém-se redução na proporção de respostas nas unidades de grau I $(3,6 \%)$ e aumento nas unidades de graus II $(6,1 \%)$ e III $(27,4 \%)$ (Tabelas 1 e 2). Nas unidades nas quais o PQT não progrediu, de um período a outro, reduziu-se o percentual de respostas para a variável entendimento de cidadania enquanto "direitos e deveres ante outros, Estado e sociedade" e aumentaram-se as demais variáveis, significando que o grau de implantação influencia positivamente nas atitudes dos usuários no que se refere ao entendimento de cidadania, em relação à variável "direitos e deveres ante outros, Estado e sociedade" (Gráfico 1).

No que se refere ao indicador entendimento de cidadania e as suas variáveis, a análise dos dados demonstrou que o grau de implantação do programa influenciou positivamente nas atitudes dos usuários, fortalecendo a identificação da cidadania com o "conjunto de direitos e deveres ante outros, Estado e sociedade”, ou seja, a visão coletivista da cidadania.

Tabela 1 - Distribuição percentual de respostas sobre cidadania por grau de implantação do PQT e seus respectivos intervalos de confiança (95\%). SMS, 1996

\begin{tabular}{l|cccccccccc}
\hline GRAU/ VARIAVEL & LI & $\begin{array}{c}\text { Grau I } \\
\mathrm{n}=712\end{array}$ & LS & LI & $\begin{array}{c}\text { Grau II } \\
\mathrm{n}=1064\end{array}$ & LS & LI & $\begin{array}{c}\text { Grau III } \\
\mathrm{n}=600\end{array}$ & $\begin{array}{c}\text { LS } \\
\text { Total } \\
\text { n=2376 }\end{array}$ \\
\hline Não sabe/não responde & 45,4 & 47,5 & 49,5 & 48,3 & 50,4 & 52,4 & 41,2 & 43,2 & 45,2 & 47,7 \\
Qualidades pessoais positivas & 25,9 & 27,7 & 29,5 & 28,2 & 30,1 & 32 & 32,4 & 34,3 & 36,3 & 30,4 \\
Cidadania como autonomia e riqueza & 4,0 & 4,8 & 5,7 & 0,9 & 1,3 & 1,9 & 3,6 & 4,3 & 5,2 & 3,1 \\
Cidadania como direitos e deveres ante & 12,6 & 13,9 & 15,4 & 12,4 & 13,7 & 15,2 & 11,7 & 13 & 14,4 & 13,6 \\
outros, Estado e sociedade & 5,3 & 6,2 & 7,2 & 3,6 & 4,4 & 5,3 & 4,3 & 5,2 & 6,2 & 5,2 \\
Outros & & & & & & & &
\end{tabular}

Legenda: LI = Limite Inferior; LS = Limite Superior

Fonte: Pesquisa de campo.

Tabela 2 - Distribuição percentual de respostas sobre cidadania por grau de implantação do PQT e seus respectivos intervalos de confiança (95\%). SMS, 1998

\begin{tabular}{|c|c|c|c|c|c|c|c|c|c|c|}
\hline GRAU/ VARIÁVEL & $\mathrm{LI}$ & $\begin{array}{l}\text { Grau I } \\
\mathrm{n}=715\end{array}$ & LS & LI & $\begin{array}{c}\text { Grau II } \\
\mathrm{n}=1078\end{array}$ & LS & $\overline{\mathrm{LI}}$ & $\begin{array}{c}\text { Grau III } \\
n=607\end{array}$ & LS & $\begin{array}{c}\text { Total } \\
n=2400\end{array}$ \\
\hline Não sabe / não responde & 58,3 & 60,3 & 62,3 & 40,9 & 42,9 & 45 & 18,8 & 20,4 & 22,1 & 42,4 \\
\hline Qualidades pessoais positivas & 16,4 & 17,9 & 19,5 & 19,4 & 21 & 22,7 & 23,2 & 24,9 & 26,7 & 21,0 \\
\hline Cidadania como autonomia e riqueza & 2,3 & 2,9 & 3,7 & 2,5 & 3,2 & 4 & 5,5 & 6,4 & 7,5 & 3,9 \\
\hline $\begin{array}{l}\text { Cidadania como direitos e deveres ante } \\
\text { outros, Estado e sociedade }\end{array}$ & 9,2 & 10,3 & 11,7 & 18,2 & 19,8 & 21,4 & 38,4 & 40,4 & 42,3 & 22,2 \\
\hline Outros & 7,5 & 8,5 & 9,7 & 11,9 & 13,2 & 14,6 & 6,9 & 7,9 & 9,1 & 10,5 \\
\hline
\end{tabular}

Legenda: LI = Limite Inferior; LS = Limite Superior

Fonte: Pesquisa de campo.

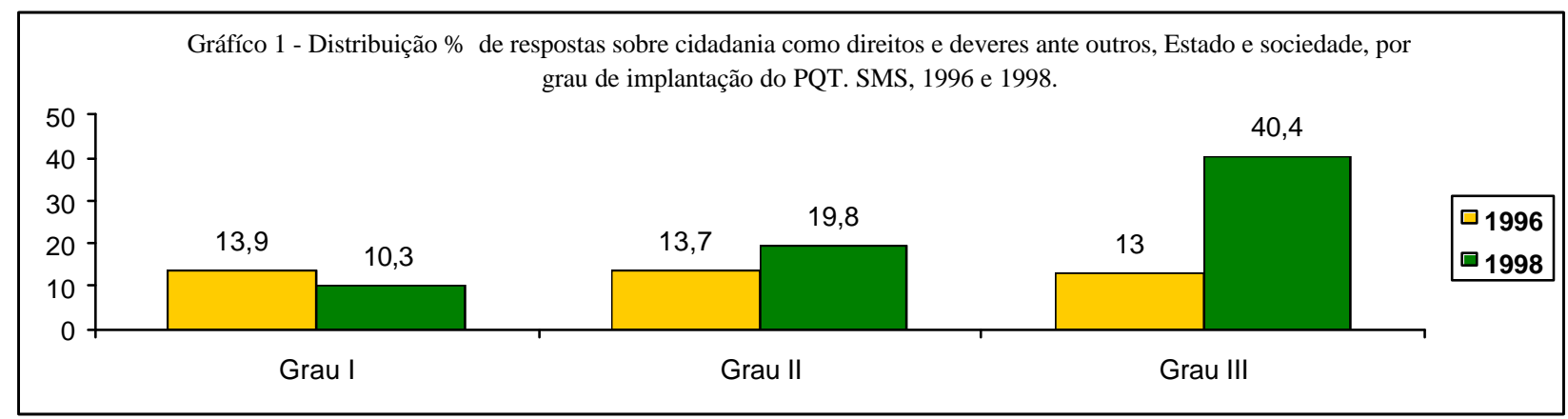




\section{Entendimento dos direitos dos cidadãos por grau de implantação do PQT e período}

No que se refere ao entendimento dos direitos dos cidadãos no Brasil por grau de implantação do PQT e período observa-se, de 1996 a 1998, redução de 5,8\% em relação ao desconhecimento e à imprecisão quanto aos direitos dos cidadãos. Em 1996, no que diz respeito à variável "não sabe/não responde" quais os direitos dos cidadãos no Brasil, não são observadas diferenças estatisticamente significantes entre as unidades com diferentes graus de implantação do PQT, o que significa que, inicialmente, o grau de implantação do PQT não influenciou as atitudes dos usuários dos serviços em relação ao desconhecimento sobre os direitos de cidadania.

Porém, em 1998, para a variável "não sabe/não responde", nas unidades com menor grau de implantação (grau I), há aumento de 7,5\% das respostas e, nas unidades de graus I e III, há redução dos percentuais de respostas dos que desconhecem os direitos dos cidadãos no País (redução de 14,8\%, nas unidades de grau II, e de $27,2 \%$, nas de grau III). Ou seja, o grau de implantação influenciou positivamente as atitudes dos usuários quanto ao conhecimento dos direitos dos cidadãos no Brasil.

Em relação à variável "direitos civis", encontram-se diferenças estatisticamente significantes entre as unidades de todos os graus e períodos, com redução, em 1998, de 9,6\%, entre as unidades de grau I, 7,2\%, entre as de grau II e 11,4\%, entre as de grau III (Tabela 4). Nos dois períodos, as unidades de grau II apresentaram os menores percentuais de respostas para esta variável, diferenciando-as das unidades de graus I e III (Tabelas 3 e 4). Isso encontra coerência com os baixos percentuais verificados nas unidades de grau II, em 1998, sobre o entendimento de cidadania como autonomia e riqueza $(3,2 \%)$. De um período a outro, os percentuais de redução encontrados nas unidades de todos os graus e, principalmente, nas de grau III, revelam que a implantação do PQT pode ter influenciado negativamente as atitudes dos usuários com referência ao entendimento dos direitos do cidadão enquanto direito civil.

Quanto à variável "direitos sociais", a análise estatística demonstra que, em 1996, há diferenças estatisticamente significantes entre as unidades de grau I $(18 \%)$ e grau II $(25,4 \%)$, entre grau II e grau III (18\%) (Tabela 3). Em 1998, também se verificam diferenças significantes para esta variável, entre as unidades de grau I (20\%) e II $(31,2 \%)$ e entre as unidades de graus II e III (20,3\%) (Tabela 4). Nos dois períodos, as unidades de grau II apresentam os maiores percentuais para esta variável indicando que o grau de implantação não influencia as atitudes dos usuários em relação à variável. De um período a outro, encontram-se pequenos aumentos percentuais para todas as unidades $(2,8 \%$, entre as unidades de grau I, 5,8\%, grau II, e 2,3\%, grau III - Gráfico 2). Entre 1996 e 1998, estes aumentos são estatisticamente significantes apenas para as unidades de grau II (Tabelas 3 e 4). O fato de os usuários dos serviços de saúde citarem os direitos sociais enquanto um direito dos brasileiros, não significa que, na prática, este direito venha sendo exercido.

No que diz respeito à variável "direitos políticos", encontram-se baixa freqüência nos dois períodos $(0,8 \%$, em 1996, e 0,9\%, em 1998). A análise desta variável por grau de implantação revela que, em 1996, não se verificam diferenças estatisticamente significantes entre as unidades com diferentes graus de implantação do PQT. Já em 1998, verificam-se diferenças apenas entre as unidades de graus I $(0,3 \%)$ e III $(1,8 \%)$ (Tabela 4). Quando se analisam as diferenças estatisticamente significantes entre os períodos, obtêm-se crescimento de 1,1\%, em 1998, nas unidades de grau III. Este discreto aumento, verificado nas unidades de grau III, não pode ser considerado um indicativo de que o grau de implantação influenciou positivamente no entendimento dos direitos políticos enquanto direitos dos cidadãos no País. Mesmo quando analisadas as respostas associadas, ou seja, direitos políticos e direitos civis, 
ou direitos políticos e direitos sociais, verificam-se baixos percentuais (Tabela 4). Os baixos percentuais verificados nos dois períodos revelam, em primeiro lugar, o distanciamento dos direitos políticos do cotidiano destes usuários, o que pode estar relacionado com as características da amostra (13,4\% de analfabetos em 1996 e 15,1\% em 1998). No Brasil, por ter sido tardiamente facultado ao analfabeto o direito ao voto, os direitos políticos passam despercebidos por este grupo. Em segundo lugar, significa que, mesmo sendo destacado o direito político pelos grupos com mais escolaridade, o simples ato de votar não significa exercer o direito político.

O exercício da cidadania e da democracia demanda e ao mesmo tempo é conseqüência da conquista de direitos políticos. No Brasil, embora a democracia política esteja instalada, a fragilidade dos partidos e a forma clientelista de exercer os direitos políticos (Kinzo \& Silva, 1999), aparentemente se apresentam como alguns dos problemas para o exercício da cidadania e da democracia. Pelo verificado empiricamente, a introdução de inovações na administração pública não modificou a atitude dos usuários em relação a esta variável.

Em resumo, os diferentes graus de implantação do PQT, embora tenham influenciado o indicador entendimento de cidadania como o conjunto de direitos e deveres ante outros, Estado e sociedade, não influenciaram o indicador entendimento dos cidadãos sobre os direitos no Brasil, enquanto direitos sociais e políticos. Mesmo quando se comparam os resultados obtidos, no total das unidades, em 1996 com aqueles de 1998, observa-se aumento de $4,0 \%$, para os direitos sociais, de $0,1 \%$ para os direitos políticos.

No que se refere à variável "expressão negativa dos direitos iii", em 1998, em relação a 1996, observam-se redução de 1,7\% nas unidades de grau I, e aumento de 4,4\%, nas unidades de grau II e 7,2\%, nas unidades de grau III (Tabela 4). Nas unidades nas quais o programa menos avançou, há tendência dos usuários de não se expressarem negativamente em relação aos direitos dos cidadãos, o que pode significar que a implantação de inovações gerenciais no serviço público, quando em graus mais avançados, pode desencadear reações nos usuários, mesmo que expressões negativas quanto aos direitos. $\mathrm{O}$ aumento, de um período a outro, desta variável pode significar uma intolerância dos usuários à negação, por parte do Estado, do cumprimento da pauta dos direitos sociais, aos quais eles têm direito.

Enfim, conforme as análises apresentadas, pode-se concluir que o grau de implantação do PQT influenciou positivamente o indicador entendimento dos direitos dos cidadãos, no que se refere às variáveis não sabe/não responde, negativamente, no que se refere aos direitos civis e quase não teve influencia em relação às variáveis direitos sociais e direitos políticos. Partindo-se do princípio de que, para demandar serviços de qualidade é necessário reconhecer-se enquanto cidadão e entender quais são os seus direitos, pode-se deduzir que esta demanda estaria fora do alcance da maioria dos usuários dos serviços públicos. Deste modo, a qualidade aceitável, segundo critérios técnicos, passaria a ser uma dádiva dos prestadores destes serviços e não um direito dos cidadãos, comprometendo assim a sustentabilidade da inovação gerencial na administração pública.

Tabela 3 - Distribuição percentual de respostas sobre os direitos dos cidadãos por grau de implantação do PQT e respectivos intervalos de confiança (95\%). SMS, 1996

\begin{tabular}{|c|c|c|c|c|c|c|c|c|c|c|}
\hline GRAU/VARIÄVEIS & LI & $\begin{array}{c}\text { Grau I } \\
N=712\end{array}$ & $\mathrm{LS}$ & LI & $\begin{array}{c}\text { Grau II } \\
\mathrm{n}=1064\end{array}$ & $\mathrm{LS}$ & LI & $\begin{array}{c}\text { Grau III } \\
n=600\end{array}$ & LS & $\begin{array}{c}\text { Total } \\
n=2376\end{array}$ \\
\hline Não sabe/não responde & $\overline{43,6}$ & 45,6 & 47,7 & 40,6 & 42,6 & 44,6 & 41,0 & 42,9 & 44,9 & 43,6 \\
\hline Direitos Civis - DC & 16,7 & 18,3 & 19,9 & 10,9 & 12,1 & 13,5 & 23,6 & 25,3 & 27,1 & 17,3 \\
\hline Direitos Sociais - DS & 16,5 & 18 & 19,6 & 23,7 & 25,4 & 27,2 & 16,5 & 18 & 19,6 & 21,3 \\
\hline Direitos Políticos - DP & 0,4 & 0,7 & 1,2 & 0,7 & 1,0 & 1,6 & 0,4 & 0,7 & 1,1 & 0,8 \\
\hline Expressão negativa dos direitos & 3,0 & 3,7 & 4,5 & 3,1 & 3,9 & 4,7 & 1,5 & 2,0 & 2,7 & 3,3 \\
\hline Respostas Imprecisas & 12,4 & 13,8 & 15,2 & 13,2 & 14,6 & 16,1 & 9,8 & 11,0 & 12,3 & 13,5 \\
\hline Outros & - & - & - & 0,2 & 0,4 & 0,7 & 0,05 & 0,2 & 0,5 & 0,2 \\
\hline
\end{tabular}

Legenda: LI = Limite Inferior; LS = Limite Superior 
Fonte: Pesquisa de campo.

Tabela 4 - Distribuição percentual de respostas sobre os direitos dos cidadãos por grau de implantação do PQT e respectivos intervalos de confiança (95\%). SMS, 1998

\begin{tabular}{|c|c|c|c|c|c|c|c|c|c|c|}
\hline GRAU/VARIÁVEIS & LI & $\begin{array}{l}\text { Grau I } \\
n=715\end{array}$ & $\overline{\mathrm{LS}}$ & $\overline{\mathrm{LI}}$ & $\begin{array}{c}\text { Grau II } \\
n=1078\end{array}$ & $\overline{\mathrm{LS}}$ & $\overline{\mathrm{LI}}$ & $\begin{array}{c}\text { Grau III } \\
n=607\end{array}$ & $\overline{\mathrm{LS}}$ & $\begin{array}{c}\text { Total } \\
n=2400\end{array}$ \\
\hline Não sabe/não responde & $\overline{51,1}$ & 53,1 & 55,2 & 26 & 27,8 & 29,6 & 14,2 & 15,7 & 17,2 & 32,3 \\
\hline Direitos Civis - DC & 7,6 & 8,7 & 9,8 & 4,1 & 4,9 & 5,9 & 12,5 & 13,9 & 15,3 & 8,3 \\
\hline Direitos Sociais - DS & 19,2 & 20,8 & 22,5 & 29,3 & 31,2 & 33 & 18,7 & 20,3 & 21,9 & 25,3 \\
\hline Direitos Políticos - DP & 0,1 & 0,3 & 0,6 & 0,5 & 0,8 & 1,3 & 1,3 & 1,8 & 2,5 & 0,9 \\
\hline Expressão negativa dos direitos & 1,5 & 2,0 & 2,6 & 7,2 & 8,3 & 9,4 & 8,1 & 9,2 & 10,5 & 6,6 \\
\hline Respostas Imprecisas & 10,8 & 12,0 & 13,4 & 15,2 & 16,7 & 18,3 & 30,4 & 32,3 & 34,2 & 19,3 \\
\hline $\mathrm{DC}+\mathrm{DS}$ & - & - & - & 0,06 & 0,28 & 0,5 & 0,2 & 0,3 & 0,7 & 0,2 \\
\hline $\mathrm{DC}+\mathrm{DP}$ & 2,2 & 2,8 & 3,6 & 7,8 & 8,9 & 10,1 & 5,0 & 5,9 & 7,0 & 6,3 \\
\hline DS+DP & 0,1 & 0,3 & 0,6 & 0,8 & 1,2 & 1,8 & 0,2 & 0,3 & 0,7 & 0,7 \\
\hline $\mathrm{DS}+\mathrm{DP}+\mathrm{DC}$ & - & - & - & 0,01 & 0,09 & 0,3 & 0,2 & 0,3 & 0,7 & 0,1 \\
\hline
\end{tabular}

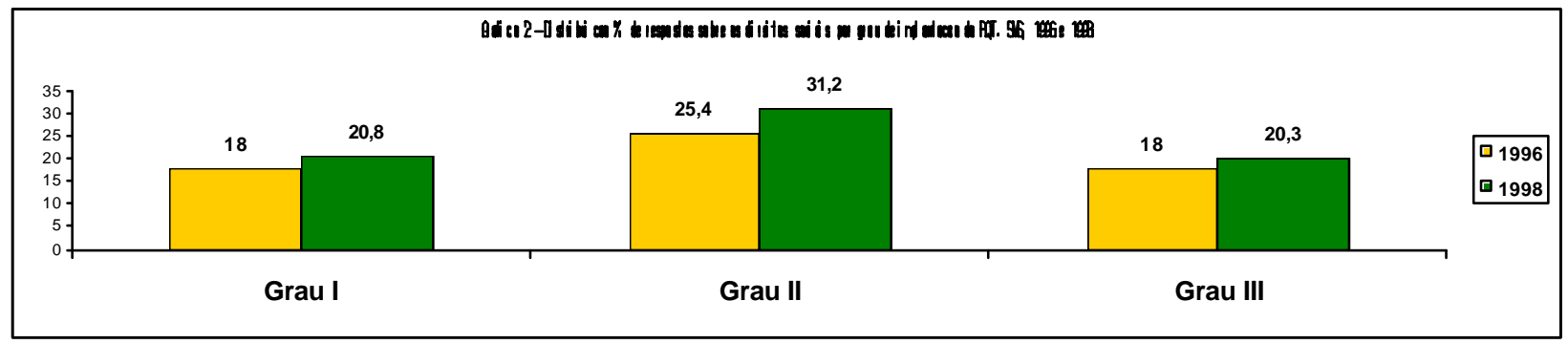

Legenda: LI = Limite Inferior; LS = Limite Superior

Fonte: Pesquisa de campo.

\section{Conclusão}

Neste trabalho discutiu-se a relação entre inovação gerencial na administração pública no contexto da reforma do estado, cidadania e direitos dos cidadãos, tomando como referências os trabalhos de Marshall (1950), Draibe (1986), Reis (1997), Turner (1993), Tenório (1998) e a Constituição Brasileira (1988) e como base empírica, o estudo realizado em serviços municipais nos quais fora implantada a inovação gerencial. O estudo objetivou conhecer o entendimento dos usuários em relação à cidadania e direitos dos cidadãos no Brasil, concluindo-se que: a) a implantação de inovações gerenciais na administração pública, no primeiro período, contribuiu para ampliar o entendimento dos usuários quanto à cidadania enquanto direitos e deveres ante outros, Estado e sociedade, porém não modificou o entendimento sobre os direitos dos cidadãos no Brasil enquanto direitos sociais e políticos; b) há uma assimilação precária quanto aos direitos constitucionalmente assegurados, assim como o possível desconhecimento da existência de mecanismos legais que podem ser acionados para assegurá-los; c) o não entendimento da maioria os entrevistados, dos direitos políticos como presentes na pauta dos direitos de cidadania no Brasil pode ser reflexo do expressivo percentual de analfabetos na amostra e do atraso com que este grupo passou a exercer o direito ao voto no País; d) a configuração das atitudes expressas pelos usuários dos serviços de saúde de Salvador pode influenciar a manutenção de inovações gerenciais no setor público, principalmente se estas inovações não forem dirigidas para estimular a compreensão deliberativa da cidadania e da saúde enquanto um direito social a ser garantido mediante efetivação de políticas públicas.

Outra conclusão que se pode chegar, a partir do estudo empírico, é que a provisão pública de serviços sociais pode servir para elevar a participação cidadã em questões que afetam diretamente a coletividade, contribuindo assim para aprofundar a democratização do 
acesso a estes serviços. Porém, isso por si só não é suficiente, para melhorar a compreensão, dependendo assim de outras variáveis como gênero e escolaridade (Mendes, 1998).

Os direitos que constituem liberdades, como os civis, implicam afastar o Estado, mas os direitos que constituem poderes, como os sociais, demandam a intervenção do Estado democraticamente gerenciado (Draibe, 1986). Isto requer a participação política de cidadãos informados sobre seus direitos, para que os mesmos possam se beneficiar das inovações no setor público. Porém, ao se transplantar do setor empresarial, acríticamente, as inovações gerenciais para aos serviços públicos, se pode estar contribuindo para aprofundar o mimetismo entre setores público e privado, para remoldar os cidadãos aos interesses hegemônicos, mantendo-se o staus quo e reafirmar a cidadania outorgada pelo Estado e os direitos enquanto dádivas dos governantes para com os governados.

Finalmente, em que pesem as distintas e, por vezes, ambivalentes definições de cidadania, este continua sendo um conceito-chave para se compreender as relações entre Estados que se reestruturam e sociedades que possuem características econômicas, políticas, sociais e culturais peculiares.

\section{Referências bibliográficas}

BARBALET, J. M. Citizenship, class inequality and resentment. In: TURNER, Bryan S (Ed.) Citizenship and Social Theory. London: SAGE,1993.

BRASIL. Ministério da Educação. Constituição da República Federativa do Brasil; promulgada em 5 de outubro de 1988. 2.ed. Rio de Janeiro: FAE, 1989.Título VIII, Capítulo II, Seção II, art. 196.

BULMER, Martin; REES, Anthony M. Conclusion: citizenship in the twenty-first century. In:

(Ed.) Citizenship today: the contemporary relevance of T. H. Marshall. London: University College Press, 1996. p. 269-283.

DEMING Edwards W. Qualidade: a revolução na administração. Tradução de Clave Comunicações e Recursos Humanos. Rio de Janeiro: Marques Saraiva, 1990.

DITTGEN, Herbert. World without borders? Reflections on the future of the Nation-state. Government and Opposition, v.34, n.2, p. 161-179, Spring 1999.

DRAIBE, Sônia Miriam. O padrão brasileiro de proteção social: desafios à democratização. Análise e Conjuntura, Curitiba, v. 8, n. 2, p. 13-19, fev. 1986.

GASTER, Lucy. Quality in public services: managers' choices. 2.ed. Buckingham: Open University Press, 1999. 149 p.

GYFORD, John. Models of change. In: _. Citizens, Consumers and Councils: local government and the public. England: Macmillan, 1991. Chapter 7, p. 152-187.

HIRSCHMAN, Albert O. De consumidor a cidadão: atividades privadas e participação na vida pública. Tradução de Marcelo M. Levy. São Paulo: Brasiliense, 1983.

KINZO, Maria D'alva G., SILVA, Simone Rodrigues da. Politics in Brazil: Cardoso's government and the 1998 re-election. Government and Opposition, v.34, n.2, p.243-262, Spring 1999.

MARCH, J.; OLSEN, J. Rediscovering Institutions: the organisational basis of politics. New York: Macmillan, 1989. Chapter 6: Institutional Reform as Public Policy, p. 95-116.

MARSHALL, Theodore. H. Citizenship and social class. Part I. London: Pluto Press, 1950.

MENDES, Vera Lúcia Peixoto Santos. Estado e Sociedade civil no Brasil: uma maltratada relação? In: ENANPAD, 22, Foz do Iguaçu (Pr). Anais... Foz do Iguaçu , 1998.

OLSON, Mancur. The logic of collective action: public goods and the theory of groups. Cambridge, Mass: Harvard University Press, 1971. 
POLLITT, Christopher. O que é qualidade dos serviços públicos. In: KLIKSBERG, Bernardo (Org.) Pobreza: uma questão inadiável; novas propostas a nível mundial. Tradução de Cláudia Schilling. Brasília: ENAP, 1994. p.347-362

PORTER, Dorothy. Health, Civilization and State: a history of public health from ancient to modern times. London and New York: Routledge, 1999.

REIS, Elisa P. On citizenship. Paper presented at the XVII WORLD CONGRESS INTERNATIONAL POLITICAL SCIENCE ASSOCIATION 27, August 17-21, 1997, Seoul, Korea. 27p. xerocop.

SANTOS, Milton. O espaço do cidadão. 4.ed. São Paulo: Nobel, 1998.

SANTOS, Wanderley Guilherme dos. Cidadania e justiça. Rio de Janeiro: Campus, 1979. Cap. 4: Do Laissez-faire repressivo à cidadania em recesso, p. 64-75.

SANDLER, Tood. Collective action: theory and applications. Ann Arbor: The University of Michigan Press, 1992.

TENÓRIO, Fernando Guilherme. Gestão social: uma perspectiva conceitual. RAP, v. 32, n. 5, p.9-23, set./out. 1998.

TURNER, Bryan S. (Ed.). Citizenship and Social Theory. London: SAGE, 1993.

VIEIRA, Liszt. Cidadania e globalização. Rio de Janeiro: Record, 1997.

\section{NOTAS:}

\footnotetext{
${ }^{\mathrm{i}}$ Os indicadores utilizados para a classificação das unidades quanto ao grau de implantação do PQT foram: a) Planejamento e avaliação descentralizados; b) Existência e funcionamento de comitês de qualidade; c) Participação dos usuários na gestão das unidades através dos Conselhos Locais de Saúde (CLS). Os dados referentes a estes indicadores foram coletados a partir dos roteiros de entrevista com representantes dos usuários nos CLS. As unidades foram classificadas em Grau I (mínimo) - quando nenhum dos indicadores estava presente; Grau II (médio) - quando estavam presentes até dois indicadores e Grau III (máximo) - quando estiveram presentes os três indicadores.

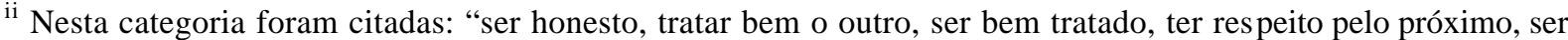
educado, inteligente, ser esclarecido, ser direito e ter uma família e uma pessoa ajudando a outra".

${ }^{\text {iii }} \mathrm{Na}$ categoria expressão negativa dos direitos se encontram respostas como: "direito nenhum, pobre não tem direito a quase nada, tem direito só ao sofrimento, direito de ser passado para trás".
} 